\title{
Revolución y rebeliones en el istmo de Tehuantepec
}

\section{María Eugenia Arias Gómez}

Instituto de Investigaciones Dr. José María Luis Mora, México

marias@institutomora.edu.mx

Héctor Luis Zarauz López, Revolución y rebeliones en el istmo de Tehuantepec, México, Instituto Mora, 2017, 399 pp. (Colección Historia Política).

Este libro es un estudio profundo que nutre con creces a la historiografía regional y nacional contemporánea de nuestro país. Desde una mirada historiográfica y con base en las ideas de José Gaos, me permito distinguir que el autor realizó con éxito las seis operaciones que un historiador requiere para la creación de una obra y que conciernen: al trabajo de la investigación y la crítica de fuentes (heurística); a la comprensión o la interpretación y la explicación del tema (hermenéutica, etiología), y a la composición o la reconstrucción y la expresión en el discurso (arquitectónica, estilística). Operaciones que se observan y que guardan un equilibrio en el texto por lo que, sin lugar a duda, recomiendo su lectura.

Al inicio, el autor plantea que hubo una continuidad del movimiento revolucionario en México que se manifestó a través de rebeliones, como fue el caso de las ocurridas en el istmo de Tehuantepec desde 1916 hasta 1924 en contra de los gobiernos carrancista, delahuertista y obregonista. Especifica que eligió este tema -central de su proyecto-, teniendo como ejes de la investigación a la revolución mexicana y a los estudios regionales; asimismo, que atendió el periodo que abarca dichos años, aunque, c) (i) (8) Atribución-No-Comercial 4.0 Internacional. 
para comprender los antecedentes, necesitó observar ciertos aspectos históricos istmeños, como los socioeconómicos que rastreó en el siglo XIX y los político-militares durante el sexenio anterior a 1916.

Zarauz realizó un estado de la cuestión y comentó que tanto el istmo, como la temática han sido poco investigados; de ahí su propósito de historiarlos, de darlos a conocer y explicarlos, a lo que agregó un poderoso motivo que influyó también: "mis vínculos personales con esta región que me llevan a quererla profundamente” (p. 21); frase que alude a su sentido de pertenencia, aclarando que el colega es un veracruzano oriundo de Minatitlán.

Para él, el istmo es geográficamente una región natural y, desde su particular perspectiva de análisis, buscó comprender su historia, atendiendo los rasgos istmeños integrales que le permitieran explicar las rebeliones y sus referentes estatales, nacionales e internacionales; además, poder "reconstruir" una región, lo que logró mediante su original mirada histórica regional. A través del libro, los lectores conocemos lo que aconteció en los cantones veracruzanos de Acayucan y Minantitlán, en el norte del istmo, y en Salina Cruz, Juchitán y otros sitios oaxaqueños, al sur de ese espacio concreto, y llegamos con el autor a esta misma conclusión: que hubo "dos procesos que en principio [fueron] distintos y en ocasiones complementarios” (p. 9).

Zarauz hizo un balance y una crítica de las fuentes que le permitieron hallar la mayor información posible a fin de conocer y comprender su objeto de estudio, para establecer cuáles fueron las causas, los hechos, los efectos y responder a los por qué, cómo, quiénes, dónde, cuándo tuvieron curso las rebeliones en el istmo de Tehuantepec. Manejó un monto notable de fuentes primarias y secundarias que hicieron viable su investigación y que darían solidez al aparato crítico de la obra. Abrevó de documentos, libros, revistas, capítulos, ensayos, artículos, entrevistas de historia oral que realizó a exrebeldes istmeños, etc. Tuvo acceso a bibliotecas locales y a las principales sitas en la Secuencia. E-ISSN 2395-8464 
Ciudad de México; a varios archivos históricos municipales, a los estatales en Veracruz y Oaxaca; asimismo, al AGN; al archivo de la SEDENA, fondo histórico de cancelados; al de la SRE; al de PEMEX; del IESU; de CONDUMEX, y al de Calles Torreblanca. Pudo manejar fuentes extranjeras, entre ellas revistas especializadas en asunto del petróleo, como la Oil and Gas Journal de Oklahoma, y la prensa británica con noticias sobre México (en la biblioteca Lerdo de Tejada de la SHCP). Trabajó archivos consulares de los Estados Unidos de América, conservados en los National Archives de Washington, a través de microfilmes en el Colegio de México. Y accedió al archivo de Weetman Pearson y al Public Record Office en Londres (pp. 18-19).

En su ejercicio metodológico, nuestro autor fue, vino, abrió, cerró, conforme analizó y sintetizó lo acontecido en el escenario istmeño; además comparó y estableció relaciones de situaciones y sucesos locales, estatales, nacionales e internacionales. De manera clara, explícita, minuciosa y sin cortapisas; con un lenguaje sencillo, fluido, en ocasiones echando mano de metáforas en su escrito, Héctor contextualizó y entramó los asuntos en el discurso, llevándonos de la mano para hacer un sugerente recorrido histórico desde su tiempo presente hasta el acontecer pretérito que rescató, observando el fenómeno de las rebeliones en el istmo de Tehuantepec, en forma lineal y a veces retrocediendo su mirada a ciertos años a fin de reiterar o enfatizar algo.

Zarauz armó su libro con una introducción, seis capítulos, un epílogo, varios apéndices, las fuentes consultadas y un índice temático; aclara que los seis apartados -que en adelante entrecomillo-, conforman tres bloques fundamentales. En el primero de estos, ubica el capítulo I "El escenario y las circunstancias", donde propone su concepto de región y la manera de construirla. Trata la geografía del istmo, los rasgos de sus habitantes; luego la demografía, el contexto económico y el devenir histórico de la región desde el siglo XIX hasta la etapa inicial de la revolución, con el fin de explicar los antecedentes de las rebeliones istmeñas que se oponen a los gobiernos emanados de la Secuencia. E-ISSN 2395-8464 
revolución. Presenta la guerra contra el huertismo y el establecimiento del constitucionalismo; a la par, atiende los esfuerzos modernizadores y la integración económica regional a circuitos del mercado internacional cuando se creó el Ferrocarril Transístmico para conocer su impacto sociopolítico en la zona. Después, en el capítulo II "La acción revolucionaria en el istmo de Tehuantepec", el autor observa la gestación y la manifestación de las rebeliones en el periodo de 1910-1916. Esboza el preludio revolucionario en Juchitán, el descontento en el istmo veracruzano y reitera la continuidad bélica contra el huertismo, asimismo el triunfo del constitucionalismo; además, enlaza el problema causado por la presión internacional y a algunos subtemas con referentes nacionales y estatales de Veracruz y Oaxaca.

En el segundo bloque, nuestro historiador desarrolla sólo un capítulo, que es el III y el más extenso en el libro. Bajo el título "Resistencia y contrarrevolución”, incluye las causas de la oposición al carrancismo; cómo son los movimientos en la región, teniendo en cuenta el asunto del petróleo; destaca la importancia de Félix Díaz, de sus seguidores y, específicamente, las rebeliones en el sur de Veracruz. Rescata y significa la participación de dos figuras locales, Cástulo Pérez y Heliodoro Charis; distingue los vínculos con el capital extranjero y el felicismo, así como la resistencia en el istmo oaxaqueño. Cierra con una referencia a cuáles son las limitaciones y las ventajas de aquellos movimientos contra los carrancistas. Si bien Zarauz considera las rebeliones que se dan en el contexto general del país, particulariza las istmeñas a nivel local y estatal tanto en Oaxaca como en Veracruz, a fin de comprender cómo y por qué ellas se ligan a otras irrupciones relacionadas con la disputa por el oro negro del país. La exposición llega hasta 1919 para tratar luego el problema de la sucesión presidencial en México, en la que contienden Venustiano Carranza y Álvaro Obregón, hecho que da pie a una rebelión nacional que afecta el curso de las manifestaciones bélicas en la región. 
En el tercer bloque, Héctor Zarauz continúa la investigación a través de los tres capítulos restantes; seguimiento que realiza con el propósito de ubicar el tema central entre 1920 y 1923. Reitera la importancia de la sucesión presidencial; atiende al movimiento de Agua Prieta, al gobierno interino de Adolfo de la Huerta, así como al constitucional de Álvaro Obregón, y da sitio a la rebelión delahuertista. Como en los bloques anteriores, la visión de Zarauz va más allá de lo político y militar, pues alcanza los motivos de la gente, de sus afiliaciones y oposiciones, e incluye las repercusiones económicas a fin de explicar los por qué y cómo de las rebeliones istmeñas. En el capítulo IV "Vuelta a las armas e integración”, nuestro autor particulariza en la acción de los rebeldes a favor del movimiento aguaprietista; retoma a Heliodoro Charis y Cástulo Pérez como cabezas locales y, a imagen de lo que acontece en el país, tras abordar aquel interinato y el triunfo obregonista, da cuenta de la pacificación e incorporación de los rebeldes istmeños a dichos gobiernos.

Uno de los capítulos más sugerente del libro es el V, el de "La reconstrucción”. Aquí, Zarauz plantea e interpreta la centralización del poder nacional; cómo se caracterizan la relación entre la región y el centro, y las rebeliones en contra de la administración de Obregón. Concibe al movimiento obrero como un 'nuevo invitado' en el escenario de los hechos; esta presencia marca una variable en la rebelión del sur veracruzano, pues adquiere un matiz distinto, en tanto la que corresponde a la parte oaxaqueña del istmo casi desaparece. Considera las ligas de los luchadores con las compañías petroleras, asimismo sus nexos a nivel local, estatal y nacional con otros movimientos. Zarauz concluye su estudio en el capítulo VI "Una nueva rebelión”, invitando al lector a que cruce 'el umbral político', a que conozca y comprenda el por qué hay 'muchas cabezas' en la región cuando acontece la rebelión delahuertista. Expone cómo los rebeldes istmeños se manifiestan con motivo de otra contienda 
electoral por el poder ejecutivo, esta vez entre Obregón y De la Huerta; cierra con 'los últimos vestigios de las movilizaciones istmeñas hasta su exterminio' en 1924.

Son muchos los aciertos del investigador en su libro; uno de ellos, el énfasis en que una región es parte de una totalidad que ayuda a la comprensión de esta; otro, la percepción de "todos los defectos del regionalismo",_como en el caso de las rebeliones istmeñas que, además del "aislacionismo", resultó imposible ampliar sus motivaciones de lucha entre otras zonas y clases sociales; una más, en tanto aquellas manifestaciones se ligaran con otros movimientos nacionales u opciones políticas más amplias, entonces podrían trascender y lograr salvarse. (p. 12 y 345). Estoy de acuerdo con lo que Zarauz y otros autores consideran, que: "la Historia está siempre en construcción” (p. 353), además con lo que expresa al final:

Hay que dejar de lado tanto los anquilosados trabajos de carácter oficial y material broncíneo, que otorgan todo tipo de bondades a la revolución y que la conciben como el gran momento de ruptura en la historia nacional, así como los estudios inscritos en el revisionismo (sean o no de carácter marxista), empeñados en encontrar el continuismo entre el antiguo régimen y los gobiernos revolucionarios, que en todos casos me parecen limitados (p. 350).

Revolución y rebeliones en el istmo de Tehuantepec es un excelente libro que, reitero, enriquece a la literatura histórica regional y nacional mexicana. El autor llevó a cabo con éxito las operaciones propuestas por José Gaos, que mencioné al principio de esta reseña, y que Álvaro Matute abrevió en tres planos: el de la investigación, la interpretación y la expresión. Planos que revelan la entrega de Zarauz al estudio, su vocación por la Historia y su amor por la región que historió.

Finalmente, cabe destacar que, en una primera etapa, Héctor Zarauz López gestó la investigación como tesis para adquirir el grado de doctor en Historia por la Universidad Nacional Autónoma de México. Además de recibir mención honorífica en el examen profesional, él obtuvo otros reconocimientos: el Premio Salvador Azuela 2005, que concede el Instituto Nacional de Estudios Históricos de las Revoluciones en México, Secuencia. E-ISSN 2395-8464 
RESEÑAS

y también la Mención Honorífica del Premio Marcos y Celia Maus, que otorgan la familia Maus y la Facultad de Filosofía y Letras de la UNAM, en el periodo 2004-2005. 